Natural Hazards and Earth System Sciences (2003) 3: 311-320

(C) European Geosciences Union 2003

System Sciences

\title{
Simulation of tsunamis induced by volcanic activity in the Gulf of Naples (Italy)
}

\author{
S. Tinti ${ }^{1}$, G. Pagnoni ${ }^{1}$, and A. Piatanesi ${ }^{2}$ \\ ${ }^{1}$ Dipartimento di Fisica, Università di Bologna, Bologna, Italy \\ ${ }^{2}$ Istituto Nazionale di Geofisica e Vulcanologia, Rome, Italy
}

Received: 19 July 2002 - Accepted: 19 September 2002

\begin{abstract}
The paper explores the potential of tsunami generation by pyroclastic flows travelling down the flank of the volcano Vesuvius that is found south of Naples in Italy. The eruption history of Vesuvius shows that it is characterised by large explosive eruptions of plinian or subplinian type during which large volume of pyroclastic flows can be produced. The most remarkable examples of such eruptions occurred in $79 \mathrm{AD}$ and in 1631 and were catastrophic. Presently Vesuvius is in a repose time that, according to volcanologists, could be interrupted by a large eruption, and consequently proper plans of preparedness and emergency management have been devised by civil authorities based on a scenario envisaging a large eruption. Recently, numerical models of magma ascent and of eruptive column formation and collapse have been published for the Vesuvius volcano, and propagation of pyroclastic flows down the slope of the volcanic edifice up to the close shoreline have been computed. These flows can reach the sea in the Gulf of Naples: the denser slow part will enter the waters, while the lighter and faster part of the flow can travel on the water surface exerting a pressure on it. This paper studies the tsunami produced by the pressure pulse associated with the transit of the low-density phase of the pyroclastic flow on the sea surface by means of numerical simulations. The study is divided into two parts. First the hydrodynamic characteristics of the Gulf of Naples as regards the propagation of long waves are analysed by studying the waves radiating from a source that is a static initial depression of the sea level localised within the gulf. Then the tsunami produced by a pressure pulse moving from the Vesuvius toward the open sea is simulated: the forcing pulse features are derived from the recent studies on Vesuvian pyroclastic flows in the literature. The tsunami resulting from the computations is a perturbation involving the whole Gulf of Naples, but it is negligible outside, and persists within the gulf long after the transit of the excitation pulse. The size of the tsunami is modest. The largest calculated oscillations are found along the innermost coasts of the gulf at Naples and at
\end{abstract}

Correspondence to: S. Tinti (steve@ibogfs.df.unibo.it)
Castellammare. The main conclusion of the study is that the light component of the pyroclastic flows produced by future large eruptions of Vesuvius are not expected to set up catastrophic tsunamis.

\section{Introduction}

Vesuvius has the longest continuously-recorded history of any volcano on Earth. The first reports are due to Pliny the Younger and are the first exceptional examples in the history of mankind of description of a volcanic eruption written by a scholar with scientific attitude: the narration is contained in two letters that are addressed by Pliny the Younger to Tacitus and account the last lifedays of his uncle, Pliny the Elder, killed by the large $79 \mathrm{AD}$ eruption that devastated the roman towns of Pompei, Herculaneum, Stabiae and Oplonti. Vesuvius eruptions can be classified into three classes of magnitudes (Rosi et al., 1987; Scandone et al., 1993): largescale plinian eruptions such as the $79 \mathrm{AD}$ event (with Volcanic Explosivity Index $V E I=5 / 5+$; see the paper by Newhall and Self, 1982, for the definition of $V E I$ ), subplinian intermediate-scale eruptions such as the 1631 event $(V E I=4)$, and small-scale, predominantly effusive eruptions, mostly characterising the post-1631 Vesuvian activity $(V E I=1-3)$. The eruptive life of the volcano can be explained by means of a simple model based on the repetition of cycles (Santacroce, 1983). Each cycle begins with a large explosive eruption (plinian or subplinian) that interrupts a period of quiescence and opens the volcanic conduit. The longer the quiescence, the larger the mass filling the magma chamber and the larger the size of the eruption. The cycle continues with a phase of persistent effusion-dominated activity controlled by the chamber refilling rate and by the conduit condition, until an explosive eruption closes the conduit again. The $79 \mathrm{AD}$ plinian eruption started a cycle after a very long repose period, and also the 1631 subplinian eruption is the first one of a new cycle or subcycle that lasted for about 300 years and was terminated by the 1944 
$V E I=3$ effusive-explosive eruption. Since 1944 Vesuvius entered a quiescent period with no activity, that could be interrupted abruptly by an intermediate-size subplinian eruption. Presently, what volcanologists expect and what has been taken as the basis for preparadness and emergency actions by the Italian Civil Protection Department is that the future eruption of Vesuvius can be at most of sub-plinian size. The envisaged scenario assumes (1) that the activity will start with a phreato-magmatic phase with repeated explosions accompanied by seismic shocks, (2) that an eruptive column up to $15-20 \mathrm{~km}$ height will later develop, with ash and coarser particle fall-out that may heavily involve an area of about $10^{4} \mathrm{~km}^{2}$ around the cone, and (3) that the column collapse will give rise to pyroclastic flows and surges travelling downslope and causing large devastation (Barberi et al., 1991; Dobran et al., 1994; Neri and Macedonio, 1996; Todesco et al., 2002). Further, partial caldera collapse can take place, and, finally phreato-magmatic explosions as the result of magma-water interaction can be the end of the eruption with associated dangerous lahars and mud flows, that may involve the Vesuvius edifice but also further areas around the volcano (Pareschi et al., 2000).

Tsunamis associated with Vesuvius activity are rare. However, according to historical documents, anomalous sea oscillations and waves in the Gulf of Naples were observed not only concomitantly to the largest eruptions (79 AD and 1631), but also to some of the smaller events, such as the cases of 14 May 1698, 17 May 1813 and April 1906 (see Tinti and Saraceno, 1993; Tinti and Maramai, 1996). There are no records of catastrophic tsunamis. The $79 \mathrm{AD}$ tsunami is described in the second letter by Pliny the Younger and occurred in the morning of the second day of eruption, that is on 25 August: the sea withdrew and a lot of fish and marine animals were left on the uncovered sea bottom. More information is available for the tsunami caused in 1631 that is depicted by several coeval sources (Anonymous, 1631; Braccini, 1632; Giuliani, 1632; Mormile, 1632; see Rosi et al., 1993 for a modern reconstruction of the event). Also this event took place in the second day of eruption on 17 December: the sea retreated by 1000 to $2000 \mathrm{~m}$ in the southern part of the Gulf of Naples, and by several tens of meters in the northern coast, and correspondingly its level lowered by some meters; coastal flooding followed and, according to some accounts, this repeated at least three times, causing damage to boats and vessels. The tsunamigenic mechanism of the Vesuvian tsunamis is not certain. They may be attributed to sea floor displacement determined by the earthquakes accompanying the volcanic activity, or to rapid inflation or deflation of the volcanic flanks involving the submarine area of the Gulf of Naples, or to pyroclastic flows affecting the sea. In 1631, the tsunami occurred during the pyroclastic flow phase, with no concomitant seismic activity. These flows were very disastrous and abundant. They formed between 10:00 and 11:00 LT of 17 December, the front separated into several branches, the most massive of which were some hundreds of meters wide and entered the sea at Torre Annunziata, Torre del Greco and Granatello (see the geo-

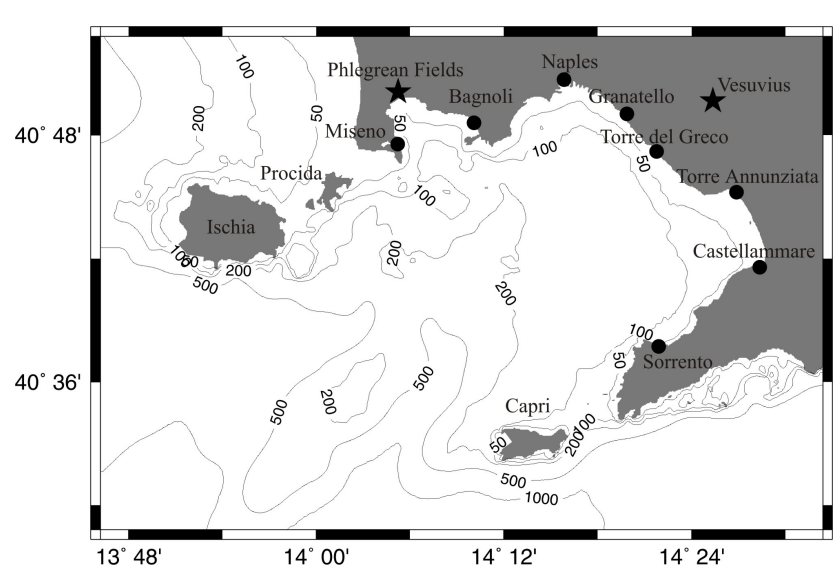

Fig. 1. Bathymetric map of the Gulf of Naples. The area shown here is the same area covered by the finite-element mesh used for tsunami simulations. Bathymetric data have been made available for this study by the Istituto di Geologia Marina di Bologna (IGMCNR). Isobath labels are in $\mathrm{m}$.

graphic positions of these localities in Fig. 1) in the form of high-density material forming small peninsulas. Historical sources narrate that sea retreat occurred earlier than the penetration of the dense pyroclastic flows in the sea water, since it occurred when the flows were still travelling down the Vesuvius flanks. One conjecture is that the main cause of this tsunami was the impact on the sea of the low-density phase of the pyroclastic flows that are known to travel much faster, and so could have affected the sea some time before the denser material reached the coastline. In this paper we will explore the tsunamigenic potential of the low- density phase of the pyroclastic flows, and we will refer to the scenario of the largest expected eruption the Italian Department of Civil Protection makes use of in order to plan emergency actions, such as the evacuation of the people living in the circum-Vesuvian area, that is one of the highest populated districts in the world (DPC, 1995). In this paper we will first study the hydrodynamic characteristics of the Gulf of Naples seen as an open basin subjected to long- wave excitation, second we will analyse the sea perturbation provoked by the light component of the pyroclastic flows that, being much less dense than the sea water, moves on it and does not penetrate beneath the sea surface, and third we will discuss our results.

\section{The Gulf of Naples}

The Gulf of Naples belongs to the Tyrrhenian sea and is a $40 \mathrm{~km}$ long and $25 \mathrm{~km}$ wide rectangular basin elongated approximately SW-NE that is embraced by four sides: the northern side begins from the islands of Ischia and Procida opposing the headland of Capo Miseno, and, running through the coasts of the Phlegrean Fields, it reaches the harbour of Naples; the second side is the mainland low-plane coastal segment from Naples to Castellammare; the third one is 

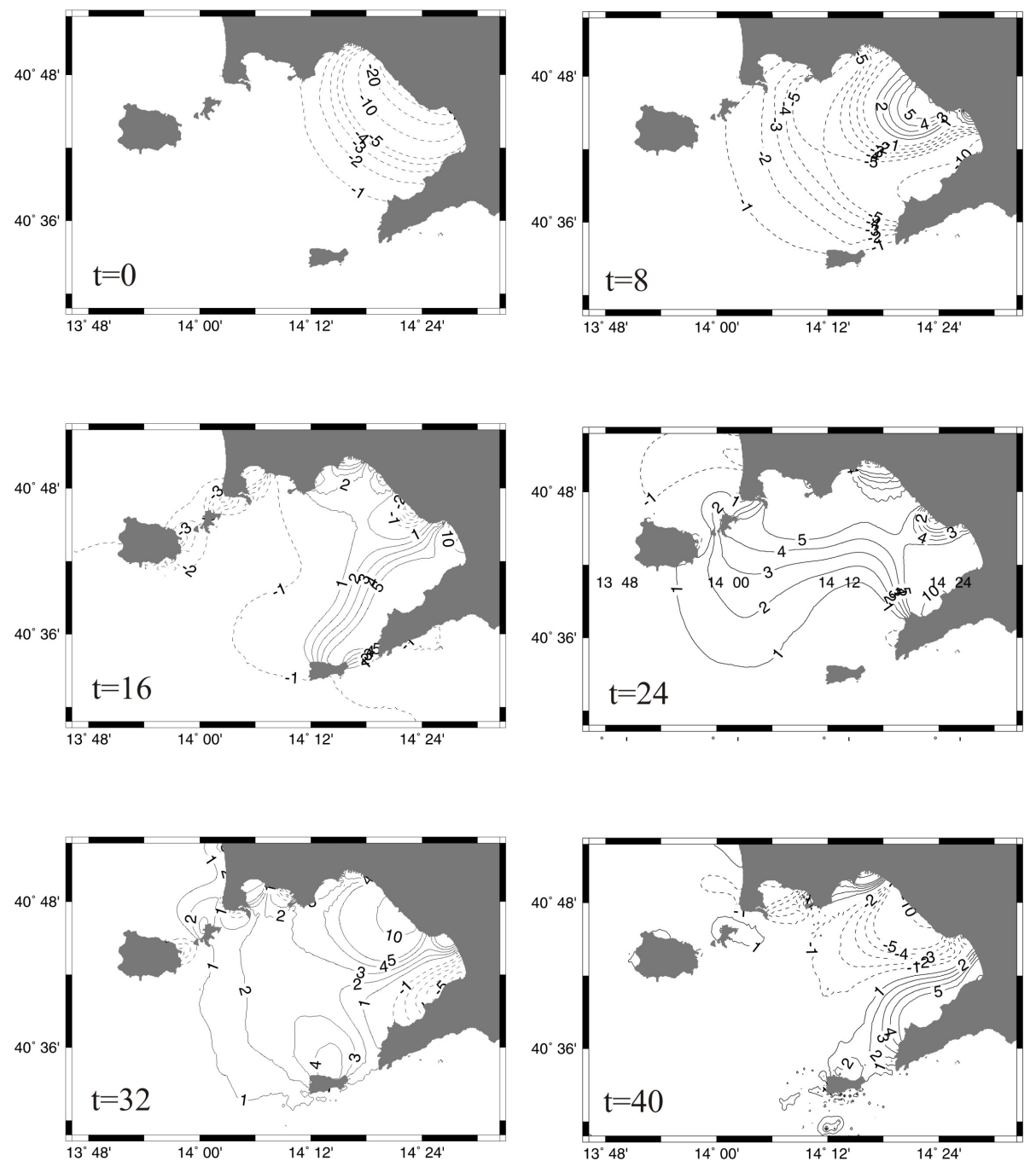

Fig. 2. Propagation of the tsunami caused by a static depression. Water elevation fields are plotted every 8 min until $40 \mathrm{~min}$ after tsunami initiation. The initial sea level depression is graphed in the upper-left-corner map of the figure corresponding to the time $t=0$. Positive (solid) and negative (dashed) contour lines of water elevation are labelled in $\mathrm{cm}$.

formed by the high coastline of the peninsula of Sorrento and continues offshore up to the island of Capri; and the last one connects ideally the open sea stretch going from Capri to Ischia. The gulf is shallow with the lowest bathymetric gradients that are found in the south-east corner at the base of the Sorrento peninsula around Castellammare $(\sim 1: 10$ nearshore slope). The sea bottom lies mostly between $100 \mathrm{~m}$ and $200 \mathrm{~m}$ depth. The offshore side of the basin can be taken to correspond to the sharp transition from $200 \mathrm{~m}$ down to $500 \mathrm{~m}$ depth: this has a quite complex shape, due mostly to a lowaltitude relief located in the sea floor at mid-distance between the islands of Ischia and Capri (see the bathymetric map in Fig. 1).

To study the main features of the propagation of long water waves in this basin we use the shallow water approximation theory and simulate a tsunami produced by an instantaneous displacement of the sea surface as the one that is associated with a submarine earthquake. Notice that by making this as- sumption we do not mean that the Gulf of Naples is an active seismic area passible of allowing tsunamigenic tectonic deformations. We use the hypothesis only as a means to run a numerical experiment involving excited long waves travelling in the basin. The non-linear shallow water equations are:

$\left\{\begin{array}{l}\partial_{t} \zeta=-\nabla \cdot[(h+\zeta) v] \\ \partial_{t} \boldsymbol{v}=-g \nabla \zeta-(\boldsymbol{v} \cdot \nabla \boldsymbol{v})-C_{f} \boldsymbol{v}|\boldsymbol{v}|(h+\zeta)^{-1}\end{array}\right.$

and are completed by the following boundary conditions:

$\boldsymbol{v} \cdot \boldsymbol{n}=\frac{g}{c} \zeta \quad$ on the open boundary

$\boldsymbol{v} \cdot \boldsymbol{n}=0 \quad$ on the solid boundary

and by the initial conditions:

$$
\begin{array}{ll}
\zeta(x, y)=\zeta_{0}(x, y) & \text { at } t=0 \\
\boldsymbol{v}(x, y)=0 & \text { at } t=0 .
\end{array}
$$



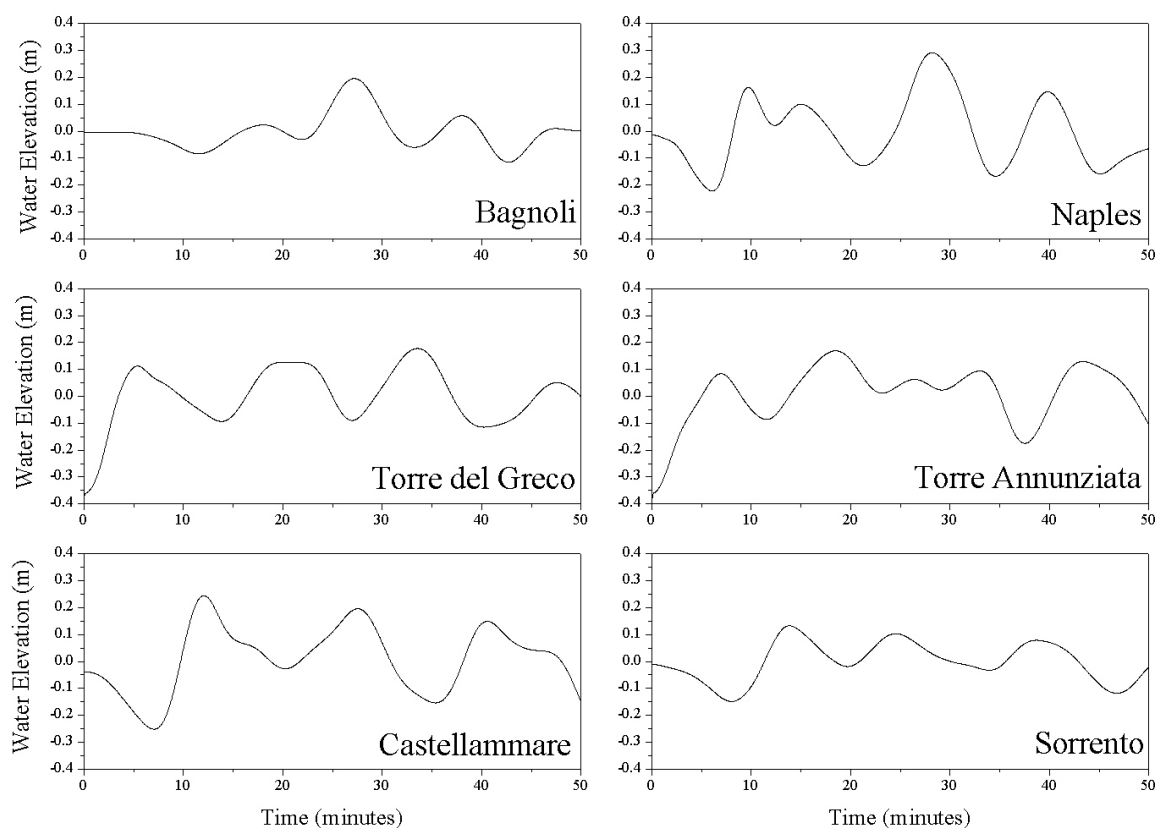

Fig. 3. Tsunami records computed at various coastal nodes of the grid until 50 min after the tsunami excitation. Node location is given in the geographic map of Fig. 1.

In the above equations $\zeta$ is the water elevation above the mean sea level, $\boldsymbol{v}=(u, v)$ is the horizontal fluid velocity vector whose $\mathrm{x}$ - and $\mathrm{y}$-components are respectively $u$ and $v$, $h$ is the basin depth, $g$ is the gravity acceleration, $c=(g h)^{1 / 2}$ is the wave celerity, $\boldsymbol{n}$ is the unit vector, normal to the boundary and directed outwardly, and $C_{f}$ is the bottom friction coefficient. In this paper we have used a depth-dependent expression for $C_{f}$ given in terms of the Manning's roughness coefficient $n$, that is:

$C_{f}=g n^{2}(h+\zeta)^{-1 / 3}$

with $n$ taken to be equal to 0.03 in units of $\mathrm{m}^{-1 / 3} \mathrm{~s}$. To solve Eqs. (1)-(3) we use the finite-element technique described in the papers by Tinti et al. (1994) and by Tinti and Gavagni (1994), implying that the basin has to be covered by a grid of triangles built in such a way to match the irregular coastline and to optimise the distribution of the times taken by the wave to cross the triangles (see the optimal criteria of mesh building for tsunami equations solvers explained by Tinti and Bortolucci, 1999). The initial excitation function $\zeta_{0}(x, y)$ is a moderate, about $40 \mathrm{~cm}$ deep, sea surface depression with elliptical shape, and with the major axis almost parallel to the coast as shown in the first map of Fig. 2. It involves a great part of the gulf and decreases toward the open sea. The tsunami propagation may be seen in snapshots of the water elevation field taken at regular intervals of $8 \mathrm{~min}$, given in the other graphs of Fig. 2. Synthetic tide gauge records computed at various coastal stations are given in Fig. 3, and the maximum and minimum water elevations calculated along the mainland coastal boundaries are graphed in Fig. 4. The

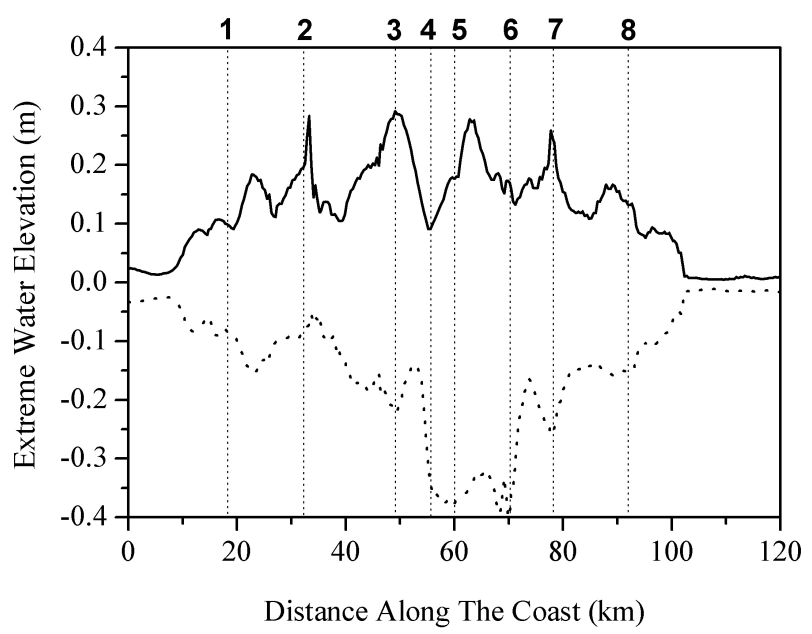

Fig. 4. Maximum (solid) and minimum (dashed) water elevation computed along the mainland coastline. Vertical lines mark the position of the localities shown in Fig. 1: 1-Miseno, 2- Bagnoli, 3Naples, 4- Granatello, 5- Torre del Greco, 6- Torre Annunziata, 7Castellammare, 8 - Sorrento. On the coast outside the gulf, the sea level remains almost unperturbed.

main points that can be learnt from this numerical experiment can be summarised as follows:

1. A perturbation that is initially set in the gulf propagates toward the Tyrrhenian sea, but the energy is partially trapped within the gulf: here a series of transversal oscillations is engendered that travel back and forth from the northern coast (Miseno-Napoli) to the Sorrento 


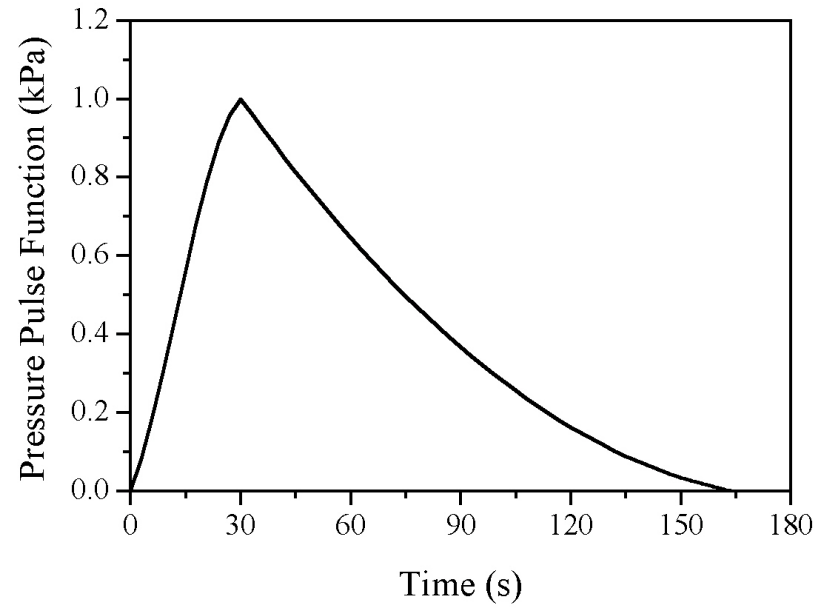

Fig. 5. Pressure pulse function used for tsunami forcing in this paper. It is plotted at the distance $r_{s}=6.7$ from the crater. It has the amplitude A of $1 \mathrm{kPa}$ and the duration $T$ of $165 \mathrm{~s}$. It propagates radially from the Vesuvius vent with amplitude decay proportional to $r^{-1}$.

peninsula and that decay slowly, leaking energy mainly through the open gulf entrance between the islands of Ischia and Capri (see Fig. 2).

2. The waves computed at the coastal nodes have dominant periods around 8-12 min (see Fig. 3). As is known, these depend upon the source size and the geometrical characteristics of the basin. In our case, since the selected source has typical length comparable with the basin's, the tsunami period and wavelength reflect the characteristics of the oscillation modes of the gulf.

3. The amplitude of the oscillations is of the same order as the initial depression. The basin does not amplify a perturbation that is initially found within the gulf, while expectedly it would amplify a tsunami incoming from the open sea. The largest positive signals are computed at Naples and to the north of Torre del Greco with other local maxima at the Phlegrean Fields and along the Sorrento peninsula (see Fig. 4), while on the mainland coasts outside the gulf the computed waves are very low. On the other hand, the minimum values are found in the central part of the gulf coast between Torre del Greco and Torre Annunziata and correspond to the initial perturbation depression.

\section{Tsunamigenic light pyroclastic flows}

Pyroclastic flows have been sometimes speculated to be the cause of tsunamis, though their potential to produce tsunamis is largely unexplored and geological and numerical studies on this topic are not frequent. The tsunami associated with the large 1815 eruption of Tambora was conjectured by some authors to be produced by massive pyroclastic flows
(Self and Rampino, 1981; Stothers, 1984; Self et al., 1984). Also for the famous catastrophic explosion of Krakatau in the Sunda Straits between Sumatra and Java that took place in 1883 pyroclastic flows have been invoked to explain the large tsunami that killed more than 30000 people living in the coastal villages of the Straits (Latter, 1981; Self and Rampino, 1981). Interaction between the sea water and pyroclastic flows was studied and classified by Cas and Wright (1991), who concentrated on the pyroclastic flow emplacement and on the properties of the ignimbrite deposits. From a tsunamigenic point of view, the mechanism of tsunami production by a dense flow of hot material that penetrates into the sea does not differ from that one associated with a landslide or rockfall entering the sea water, since the temperature of the moving body is ineffectual: the penetrating body displaces the water moving it upward. What matters most are the body volume and velocity: the larger the volume and the closer the body velocity is to the celerity of the tsunami, the greater will be the amplitude of the generated water waves (see Tinti and Bortolucci, 2000; Tinti et al., 2001). Therefore the process can be modelled by the same numerical codes, or by variants of them, that are used to simulate landslideinduced tsunamis (see the study on waves generated by subacqeous pyroclastic flows by de Lange et al., 2001). On the other hand, light pyroclastic flows tend to float and are expected to travel on the sea surface over long distances until they slow down and deposit on the sea floor. Their action on the sea surface is hypothesised to be similar to the effect of an overpressure pulse that is due both to the weight of the flowing material (static pressure) and to the vertical velocity against/away from the sea surface (dynamic pressure), and that depends on the instantaneous dynamic condition of the pyroclastic flow. Hence modelling tsunamis implies modelling the pyroclastic flows with sufficient detail to compute the data on static and dynamic pressure, say $P_{s}(x, y, t)$ and $P_{d}(x, y, t)$, at the sea surface that are to be used as input for tsunami simulations. The overpressures exert a vertical force on the the sea surface and cause it to move from the equilibrium level. Let us suppose that there is proportionality between the forcing pressure pulse and the water elevation $\zeta_{f}$, that is $\zeta_{f}(x, y, t)=\alpha P_{f}(x, y, t)$ where the subscript $f$ denotes the total forcing pressure that can be taken as the sum of $P_{s}(x, y, t)$ and $P_{d}(x, y, t)$. The coefficient $\alpha$ can be determined by balancing the pressure $P_{f}(x, y, t)$ with the pressure exerted by a column of water of height $\zeta_{f}(x, y, t)$, i.e.:

$\zeta_{f}(x, y, t)=-(\rho g)^{-1} P_{f}(x, y, t)$,

where $\rho$ is the density of the sea water. It is seen that a positive pressure pulse induces a sea level drop, and that conversely a negative pressure forces the sea surface to rise. The long wave hydrodynamic equations accounting for the surface forcing can be written in the following form:

$$
\left\{\begin{array}{l}
\partial_{t} \zeta=\partial_{t} \zeta_{f}-\nabla \cdot[(h+\zeta) \boldsymbol{v}] \\
\partial_{t} \boldsymbol{v}=-g \nabla \zeta-(\boldsymbol{v} \cdot \nabla \boldsymbol{v})-C_{f} \boldsymbol{v}|\boldsymbol{v}|(h+\zeta)^{-1}
\end{array}\right.
$$


that differ from the set of Eqs. (1) only for the presence of the forcing term in the continuity equation, that is considered here an input function, known a priori. The boundary conditions (2) are still valid here, but the initial conditions should be replaced by:

$$
\begin{array}{ll}
\zeta(x, y)=0 & \text { at } t=0 \\
\boldsymbol{v}(x, y)=0 & \text { at } t=0
\end{array}
$$

stating that the sea is in a still state before pyroclastic flows force it to move by acting on the surface. Mathematically the system of Eqs. (5) together with the conditions (2) and (6) is similar to the one governing waves excited by a submarine landslide. In this latter case the forcing term $\partial_{t} \zeta_{f}$ depends on the landslide dynamics (see e.g. the simulation of the Holocene tsunami produced by the lateral collapse of Stromboli, Italy, by Tinti et al., 2000). In conclusion, we observe that numerical codes used to simulate tsunamis produced by moving bodies can be utilised to study also tsunamis generated by pyroclastic flows, and this holds both in the case of very dense flows penetrating underwater, since there is physical analogy between the two processes, as well as in the case of light flows running on the sea surface, since the analogy resides in the mathematical structure of the governing systems of differential equations. Notice further that the forcing term has to be computed by means of the appropriate set of equations, and these are very different because they are dictated by the landslide dynamics and by the pyroclastic flows dynamics respectively.

\section{Forcing pressure pulse of pyroclastic flows}

Modelling pyroclastic flows is complex since it entails the modelling of the volcanic eruption process including the magma ascent in the volcanic conduit and the following dispersal of a multiphase mixtures in the atmosphere, describing the formation, sustainment and subsequent collapse of the eruptive column. The time evolution of the column may be computed through the full set of the thermodynamic NavierStokes equations applied to a system comprising gases and various particulate phases. The scenario of a large eruption of Vesuvius has been explored several times and progressively refined by modellers in the recent past years (see Dobran 1992; Dobran et al., 1994; Neri and Macedonio, 1996). The latest contribution is the work by Todesco et al. (2002) complemented by the companion study by Esposti Ongaro et al. (2002), where the development of plume from the Vesuvius vent and the propagation of pyroclastic flows down Vesuvius slopes are analysed by means of a sophisticated numerical model especially developed to deal with mixtures of coarse and fine particles and gases. The model is a 2$\mathrm{D}$ code solving equations in a cylindrical coordinate system, and therefore simulates eruptions with cylindrical symmetry around the volcanic cone: variables depend on the radial distance from the vent $r$ and on the vertical coordinate $z$, but not on the azimuthal angle. This is certainly a limitation since all historical eruptions showed substantial departure from axial symmetry. Considering however that the model handles not only purely isotropic eruptions, but also flows that are confined within a sector of finite amplitude $\Delta \theta$, the approximation is acceptable, since it enables one to explore the main features of the process. The goal of those authors is to examine Vesuvian eruptions in different conditions (various mass eruption rate, magma water content, magma temperature influencing the pressure and composition of the mixture at the vent) and to calculate the evolution of the flow with special attention to the bottom layer close to the ground, where pyroclastic flows are expected to have major impact on the humans and the environment (see Baxter et al., 1998; Cioni et al., 2000). In particular, Esposti Ongaro et al. (2002) provide time histories of the static and dynamic pressure $P_{s}$ and $P_{d}$ at surface points placed at various radial distances from the volcanic vent. We note here that their simulation domain is confined to radial distances up to $7.5 \mathrm{~km}$ roughly corresponding to the area comprised between the Vesuvius vent and the shoreline. In their paper it is shown that the time variations of pressure in the proximal area is quite complex: it consists of a series of pulses reflecting closely the ascensional dynamics of the plume, which is characterised by typical episodes of fountain formation and collapse. But at larger distances the time evolution simplifies almost to a single well defined pulse, which is typical of advection: it corresponds to the passage of low-density pyroclastic flow propagating downslope. For the purpose of this study we have assumed that the tsunami is excited by the light component of the pyroclastic flow and have modelled the tsunami forcing function $\zeta_{f}(r, t)$ basing on the results of the paper by Esposti Ongaro et al. illustrated above. We have considered a single pressure pulse $P(r, t)$ travelling downslope with constant radial velocity over a sector centered on the crater. The pulse duration is supposedly constant and its amplitude decreases inversely with the distance from the crater, i.e.:

$$
P(r, t)=\left(\frac{r_{s}}{r}\right) f(t-r / V) \quad r \geq r_{s} .
$$

Here $r_{s}$ denotes the shortest distance of the shoreline from the Vesuvius vent, and accordingly the domain $r<r_{s}$ corresponds to dry land, and $V$ is the velocity of the advancing pyroclastic flow. The function $f$ is the pressure function given in Fig. 5: it describes a single pulse having a sharp rise front and a slower decay with duration $T=165 \mathrm{~s}$ and amplitude $A=1 \mathrm{kPa}$ at the distance $r_{s}=6.7 \mathrm{~km}$ from the vent. The pulse shape, duration, amplitude and velocity are calculated roughly from Esposti Ongaro et al.'s analysis (2002), and in the present study are taken as plausible values of pressure variations induced by light pyroclastic flows associated with large Vesuvian eruptions, that are susceptible to decrease/increase at most by a factor of 5 in a future plinian or subplinian eruption of Vesuvius. 

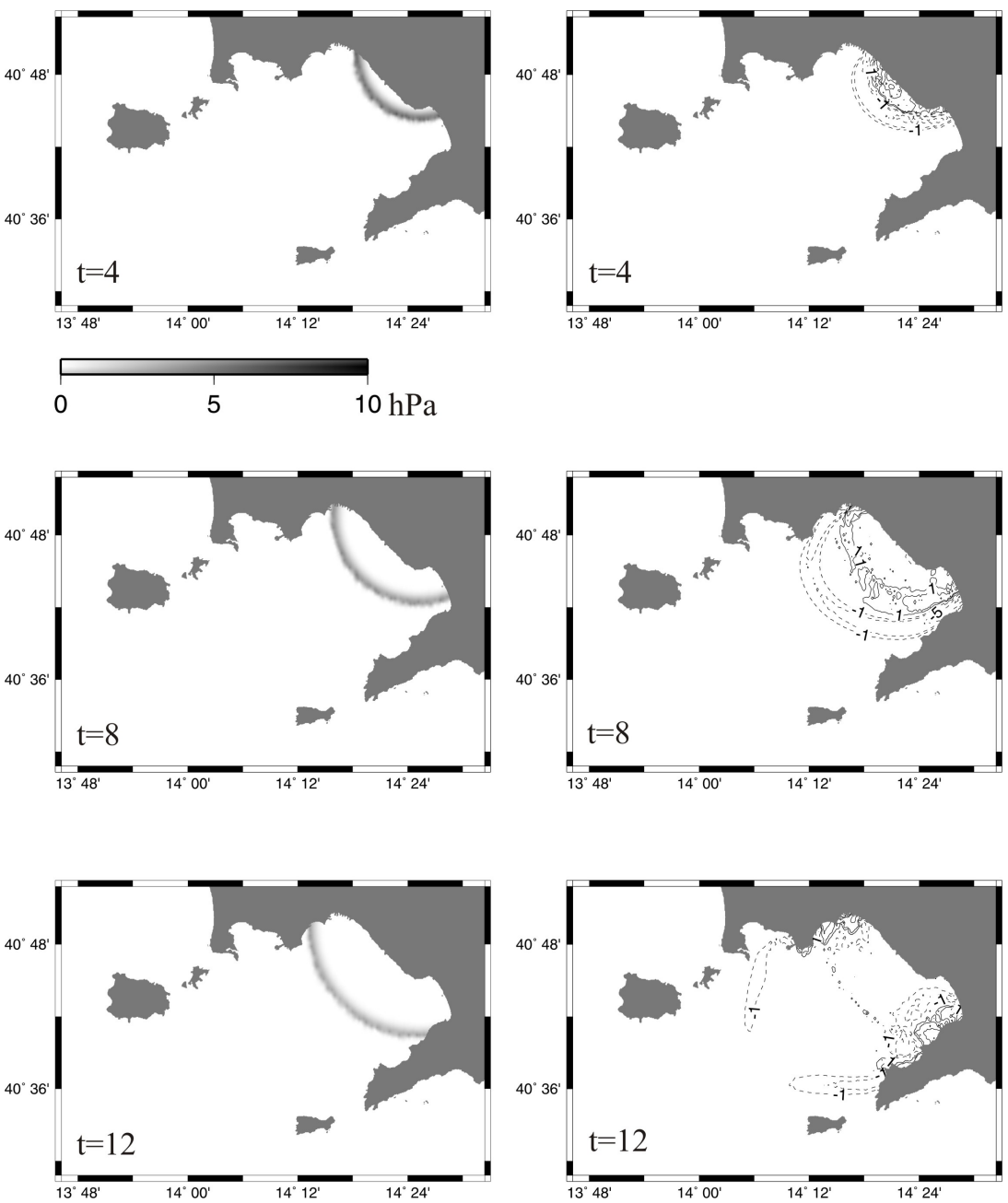

Fig. 6. Pressure pulse fields (on the left) computed at different times, given in minutes. The palette for pressure values ranges from 0 to $10 \mathrm{hPa}$. Water elevation fields (on the right) computed at the same instants. Time is measured from tsunami origin time and not from the beginning of the eruption. Contour line labels are in $\mathrm{cm}$. Positive/negative elevation curves are solid/dashed lines.

\section{Tsunami simulation}

The forcing pressure pulse is supposed to propagate radially outward over a sector embracing the whole Gulf of Naples, advancing with constant velocity $V$ according to the law (7). At any instant, forcing is confined spacely within an annulus centered on the Vesuvius crater with radial width $\Delta r=V T$, and the annulus moves outward at constant speed $V$, that in the example treated here is taken to be equal to $15 \mathrm{~m} / \mathrm{s}$ (see maps on the left side of Fig. 6). The consequent forced change of the sea surface elevation $\zeta_{f}$ is computed through the conversion relationship (4), and the excited tsunami is calculated by solving Eqs. (5) and (6) with the finite-element technique. The computational mesh covers the whole area of the Gulf of Naples depicted in the map of Fig. 1. This mesh, that has been also used for the numerical experiment described in the above Sect. 2 , is formed by over 4500 nodes and 8500 triangles and has a coastal resolution of about $300-400 \mathrm{~m}$. Figure 6 displays side by side the forcing pressure pulse and the water elevation fields at various times, with the pulse still moving in the innermost part of the gulf. Notice that the time is measured here from the instant in which the pressure pulse reaches the sea and begins to excite the tsunami, and not from the beginning of the eruption. The overpressure induced by the pyroclastic flow forces the sea level to drop, and consequently the leading tsunami wave is a sea level depression. The former runs faster than the pyroclastic flow in the central part of the gulf which is deeper, but moves circa at the same speed in the nearshore belt which is shallower. This is clearly visible by comparing the instantaneous positions of the leading wave and the pressure pulse in the maps of Fig. 6 corresponding to the same times. By inspecting the central plots computed for $t=8 \mathrm{~min}$ it can be observed that the leading front and the pressure pulse almost overlap in the upper and lower corner of the gulf where the towns of Naples and Castellammare are found, while they are already distinctly separated in the middle of the gulf, where water waves travel at higher speed. This observation is relevant since it tells us that the local Froude number is close to one in the inner shore belt and tends to be progressively 

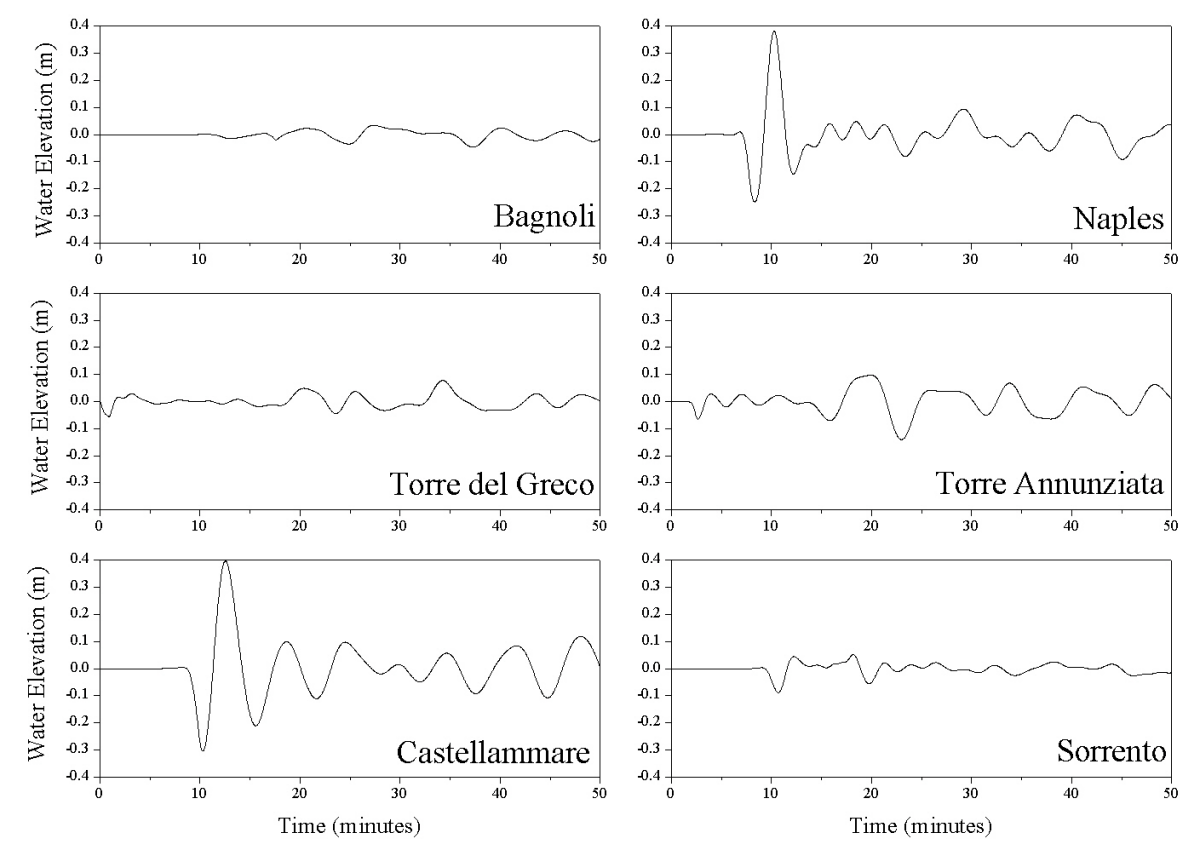

Fig. 7. Tsunami time histories calculated at various coastal stations. To favour comparison, the same nodes of Fig. 3 have been selected. Location of these stations can be seen in the map of Fig. 1.

smaller offshore, which has effect on the efficiency of the tsunamigenic mechanism (Tinti and Bortolucci, 2000; Tinti et al., 2001). Notice further that the pulse exerts its direct influence over a rather narrow annulus, having radial width $V T$ that is smaller than $3 \mathrm{~km}$. The water elevation fields show that only the leading trough propagates with distinct coherent shape. Behind it, the wave pattern is rather complex: the perturbation is small in the offshore part of the gulf and is more relevant nearshore where it moves as a series of edge waves.

Tide gauge records computed along coastal stations through the numerical model are graphed in Fig. 7 in the first $50 \mathrm{~min}$ after tsunami start. The signal is seen first at Torre del Greco and Torre Annunziata that are closer to the Vesuvius cone and are the first stations to be attacked by the pyroclastic flow. At Torre Annunziata the tsunami signal is a train of 3-4 short-period ( $\sim 3 \mathrm{~min})$ small-amplitude $(\sim 5 \mathrm{~cm})$ oscillations, that is followed by larger waves $(>10 \mathrm{~cm})$ at about 15-20 min. At around 7-8 min. the tsunami arrives almost simultaneously at Naples and Castellammare: in both places the first arrivals are the largest waves with peak-to-peak amplitude about $60 \mathrm{~cm}$ and $70 \mathrm{~cm}$, respectively. Oscillations have here main period slightly larger than $5 \mathrm{~min}$. The last stations of Fig. 6 to be reached by the tsunami are Sorrento and Bagnoli. The marigrams show that after the passage of the main front responsible of the first few waves the tail of oscillations persists for a long time and decays quite slowly, which is a sign that the basin tends to trap long-wave energy as was already observed in the case discussed in Sect. 2 .

Figure 8 portrays minima and maxima computed along the mainland coast. The curves exhibit narrow peaks: the

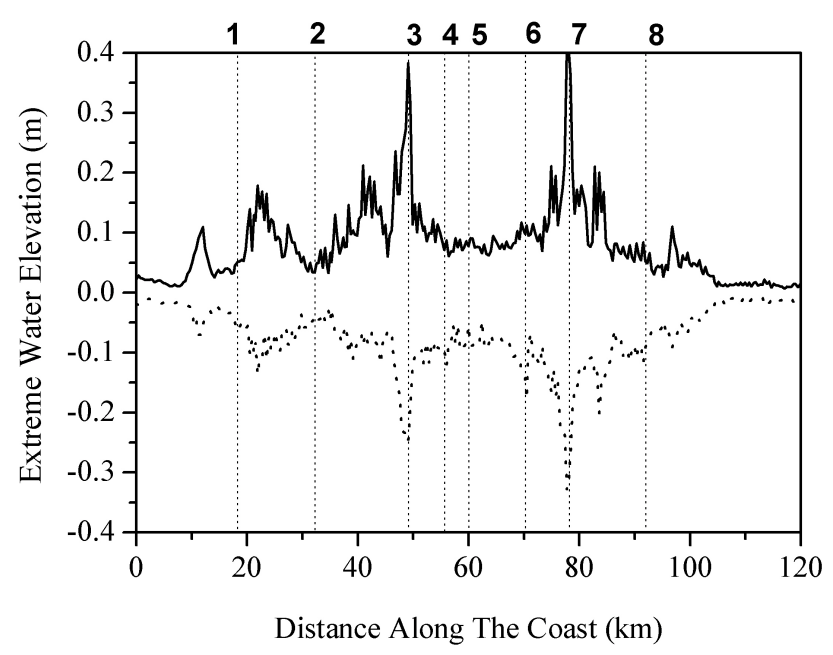

Fig. 8. Curves of minimum and maximum water elevation calculated along the coast of the mainland. Vertical lines mark the position of the main localities of the gulf: correspondence between numbers and localities is given in the caption of Fig. 4. Observe that the perturbation is confined within the gulf.

highest correspond to the stations of Naples and of Castellammare (number 3 and 7, respectively in the figure). Other maxima and minima are found in correspondence with the saddle between Procida and Capo Miseno, of the gulf of Pozzuoli (Phlegrean Fields) and west of Naples. It is seen that there are large local variations. The size and sharpness of the peaks of Castellammare and of Naples can be explained by two main factors: (1) one concerns the geometry of the basin 
coastline that forms right-angle corners here and enhances wave reflection; (2) the other regards the tsunami generation process that takes place here in a regime of local Froude number close to the critical value of 1 , which is the most favourable case for water wave formation.

The tsunami amplitude we have computed is modest. Such a tsunami cannot be considered hazarduous, and in terms of the Ambraseys-Sieberg scale adopted for European tsunamis (see e.g. Tinti and Maramai, 1996) its intensity would be not larger than 2. The question arises whether a larger tsunami could have been computed if we had selected a different set of parameters for the forcing pressure pulse, i.e. a different amplitude $A$, or duration $T$, or travelling speed $V$, etc. A detailed sensitivity analysis is out of the scope of the present paper, and will be left to further studies. We believe that varying such parameters would have an influence on the computed tsunami size. The most influencing parameter is expected to be the pulse amplitude: the larger it is, the larger the amplitude of the excited tsunami is expected to be. But also the velocity of the pulse is a crucial parameter since tsunami excitation is much more effective when the pulse speed is close to the velocity of the tsunami front, as already noted. Hence varying parameters, provided however that they remain within the reasonable limits required by the pyroclastic flow dynamics, will probably produce more sizeable tsunamis. We believe however that it is unlikely that the calculated waves will be large enough to be catastrophic. Phrased more properly, it can be stated that, if a large plinian or subplinian eruption of Vesuvius occurs, the associated low-density component of the pyroclastic flows are expected to produce a tsunami that affects the Gulf of Naples, but the tsunami is expectedly not catastrophic, and it will be at most as large as the one observed in the second day of the 1631 eruption.

\section{Conclusions}

In this paper we have studied tsunami excitation and propagation in the Gulf of Naples. The main hydrodynamic features of this basin have been examined by studying the long waves generated by an initial static depression of the sea surface located in the inner part of the gulf. It has been shown that internal sources can excite eigenmodes of oscillation with the largest amplitudes observed on the internal coasts. Pyroclastic flows associated with large Vesuvian eruptions have characteristics that have been analysed by means of numerical models by recent papers in the literature. We have supposed that light flows can travel over substantial distances on the sea surface. The overload associated to their motion can be modelled as a moving pressure pulse that is capable of producing water waves. The characteristics of such pulse have been inferred from the literature. We have explored only the case of pressure pulse corresponding to a given set of parameters, that we consider to be representative of pyroclastic flows of a big eruption of Vesuvius. The generated tsunami has been simulated by means of a finite-element model solv- ing the equations of the shallow water theory with a pressure forcing term. The oscillations resulting from the simulations are larger in the gulf and almost negligible outside. Their amplitude is small, and we believe that even changing the set of the parameters of the forcing pressure pulse function, the size of the resulting tsunami could be larger yet, but not too larger than the one computed in this paper.

Acknowledgements. This work was carried out on funds from the Gruppo Nazionale di Vulcanologia (GNV) of the Istituto Nazionale di Geofisica e Vulcanologia (INGV). The authors wish to thank G. Bortoluzzi and the Director of the Istituto di Geologia Marina of the Consiglio Nazionale delle Ricerche (IGM-CNR) of Bologna for the bathymetric data of the Gulf of Naples extracted from the IGM data base.

\section{References}

Anonymous: Relazione dell'incendio del Vesuvio del 1631, in: "Documenti inediti", edited by Riccio L., Giannini e Figli, Napoli, 1889, 513-521 (in Italian), 1631.

Barberi, F., Macedonio, G., Pareschi, M. T., and Santacroce, R.: Mapping the tephra fallout risk: an example from Vesuvius (Italy), Nature, 344, 142-144, 1991.

Baxter, P. J., Neri, A., and Todesco, M.: Physical modelling and human survival in pyroclastic flows, Natural Hazards, 17, 163176, 1998.

Braccini, G. C.: Dell'incendio fattosi sul Vesuvio a XVI Dicembre MDCXXXI e delle sue cause ed effetti, con la narrazione di quanto è seguito in esso per tutto marzo 1632 e con la storia di tutti gli altri incendi, nel medesimo monte avvenuti, Secondino Roncagliolo, Napoli, 104 pp., (in Italian), 1631.

Cas, R. and Wright, J. V.: Subacqueous pyroclastic flows ignimbrites: an assessment, Bull. Volcanol., 53, 357-380, 1991.

Cioni, R., Gurioli, L., Sbrana, A., and Vougioukalakis: Precursory phenomena and destructive events related to the Bronze Age Minoan (There, Greece) and the A.D. 79 (Vesuvius, Italy) Plinian eruptions; inferences from the stratigraphy in the archaeological areas, in: "The archaeology of geological catastrophes", Geol. Soc. London Spec. Publ 171, 123-141, 2000.

De Lange, W. P., Prasetya, G. S., and Healy, T. R.: Modelling of tsunamis generated by pyroclastic flows (ignimbrites), Natural Hazards, 24, 251-266, 2001.

Dobran, F.: Nonequilibrium flow in volcanic conduits and applications to the eruptions of Mt.St.Helens on 18 May 1980 and Vesuvius in AD 79, J. Volcanol. Geotherm. Res., 49, 285-311, 1992.

Dobran, F., Neri, A., and Todesco, M.: Assessing pyroclastic flow hazard at Vesuvius, Nature, 367, 551-554, 1994.

DPC: Pianificazione territoriale di emergenza dell'area Vesuviana, Dipartimento di Protezione Civile Report, Rome (in Italian), 1995.

Esposti Ongaro, T., Neri, A., Todesco, M., and Macedonio, G.: Pyroclastic flow hazard assessment at Vesuvius (Italy) by using numerical modeling. II. Analysis of flow variables, Bull Volcanol, 64, 178-191, 2002.

Giuliani, G.: Trattato del Monte Vesuvio e de' suoi incendii, Egidio Longo, Napoli, 254 pp., (in Italian), 1632.

Latter, J. H.: Tsunamis of volcanic origin: summary of causes, with particular reference to Krakatoa, 1883, Bull. Volcanol., 44, 468490, 1881. 
Mormile, G.: L'incendio del Monte Vesuvio, e delle straggi, e rovine, che ha fatto ne' tempi antichi e moderni, infine a 3 di marzo 1632, con nota di tutte le relazioni stampate fino ad oggi del Vesuvio, raccolte da Vincenzo Bove, Egidio Longo, Napoli, 48 pp., (In Italian), 1632.

Neri, A. and Macedonio, G.: Numerical simulation of collapsing volcanic columns with particles of two sizes, J. Geophys. Res., 101, 8153-8174, 1996.

Newhall, C. F. and Self, S.: The volcanic explosivity index (VEI): an estimate of explosive magnitude for historical eruptions, J. Geophys. Res., 87, 1231-1238, 1982.

Pareschi, M. T., Favalli, M., Giannini, F., Sulpizio, R., Zanchetta, G., and Santacroce, R.: 5 May 1998 debris flows in circumVesuviuan areas (southern Italy): insights for hazard assessment, Geology, 28, 639-642, 2000.

Rosi, M., Santacroce, R., and Sheridan, M. F.: Volcanic Hazard, in: "Somma-Vesuvius", edited by Santacroce R., Progetto Finalizzato Geodinamica, Quaderni de "La Ricerca Scientifica", CNR, Rome, 8, 197-220, 1987.

Rosi, M., Principe, C., and Vecci, R.: The 1631 Vesuvius eruption. A reconstruction based on historical and stratigraphical data, J. Volcanol. Geotherm. Res., 58, 151-182, 1993.

Scandone, R., Giacomelli, L., and Gasparini, P.: Mount Vesuvius: 2000 years of volcanololgical observations, J. Volcanol. Geotherm. Res., 58, 5-25, 1993.

Self, S. and Rampino, M. R.: The 1883 eruption of Krakatau, Nature, 294, 699-704, 1981.

Self, S., Rampino, M. R., Newton, M. S., and Wolff, J. A.: Volcanological study of the great Tambora eruption of 1815 , Geology, 12, 659-663, 1984.

Stothers, R. B.: The great Tambora eruption in 1815 and its aftermath, Science, 224, 1191-1198, 1984.

Tinti, S. and Saraceno, A.: Tsunamis related to volcanic activity in Italy, in: "Tsunamis in the world", edited by Tinti S., Advances in Natural and Technological Hazards Research, Kluwer Academic Publishers, Dordrecht, The Netherlands, 1, 43-63, 1993.

Tinti, S., Gavagni, I., and Piatanesi. A.: A finite-element numerical approach for modelling tsunamis, Annali di Geofisica, 37, 10091026, 1994.

Tinti, S. and Gavagni, I.: A method for reducing the propagation noise in FE modeling of tsunamis, Science of Tsunami Hazards, 12, 77-92, 1994.

Tinti, S. and Maramai, A.: Catalogue of tsunamis generated in Italy and in Côte d'Azur, France: a step towards a unified catalogue of tsunamis in Europe, Annali di Geofisica (Errata Corrige, Annali di Geofisica, 40, 781) 39, 1253-1299, 1996.

Tinti, S. and Bortolucci, E.: Strategies of optimal grid generation for finite-element tsunami models, Proc. International Conference on Tsunamis, Paris, 26-28 May 1998, 269-294, 1999.

Tinti, S. and Bortolucci, E.: Analytical investigation on tsunamis generated by submarine slides, Annali di Geofisica, 43, 519-536, 2000.

Tinti, S., Bortolucci, E., and Romagnoli, C.: Computer simulations of tsunamis due to flank collapse at Stromboli, Italy, J. Volcanol. Geotherm. Res., 96, 103-128, 2000.

Tinti, S., Bortolucci, E., and Chiavettieri, C.: Tsunami excitation by submarine slides in shallow-water approximation, Pure Applied Geophysics, 158, 759-797, 2001.

Todesco, M., Neri, A., Esposti Ongaro, T., Papale, P., Macedonio, G., Santacroce, R., and Longo, A.: Pyroclastic flow hazard assessment at Vesuvius (Italy) by using numerical modeling. I. Large-scale dynamics, Bull. Volcanol., 64, 155-177, 2002. 